\title{
Mechanical properties of rotary swaged steel components
}

\author{
Dhia Charni' ${ }^{1}$ (I) S Svetlana Ortmann-Ishkina ${ }^{2,4} \cdot$ Marius Herrmannn ${ }^{2,3,4} \cdot$ Christian Schenck $^{2,3,4} \cdot$ Jérémy Epp ${ }^{1,3}$
}

Received: 20 January 2021 / Accepted: 27 May 2021 / Published online: 5 July 2021

(c) The Author(s) 2021

\begin{abstract}
The radial infeed rotary swaging is widely used as a diameter reduction forming process of axisymmetric workpieces, improving the mechanical properties with excellent near net shape forming. In the present study, rotary swaging experiments with different parameter setups were performed on steel tubes and bars under different material states and several resulting property modifications were investigated such as stress-strain curve, hardness, fatigue strength and surface residual stresses. The results show a significant work hardening induced by the rotary swaging process and an improvement in the static and dynamic mechanical properties was observed. Furthermore, the hardness distribution was homogenous in the cross section of the rotary swaged workpieces. Moreover, depending on the process conditions, different residual stresses distribution were generated along the surface.
\end{abstract}

\section{Mechanische Eigenschaften rundgekneteter Stahlkomponenten}

\section{Zusammenfassung}

Das Rundkneten mit radialer Zustellung wird häufig als Umformverfahren zur Durchmesserreduzierung von achsensymmetrischen Werkstücken verwendet und verbessert die mechanischen Eigenschaften bei hervorragender endkonturnaher Formgebung. In der vorliegenden Studie wurden Rundknetexperimente mit verschiedenen Parametereinstellungen an Stahlrohren und -stäben bei verschiedenen Materialzuständen durchgeführt und unterschiedliche resultierende Eigenschaftsänderungen wie Fließkurve, Härte, Dauerfestigkeit und Oberflächeneigenspannungen untersucht. Die Ergebnisse zeigen eine signifikante Kaltverfestigung durch den Rundknetprozess als auch eine Verbesserung der statischen und dynamischen mechanischen Eigenschaften konnte beobachtet werden. Die Härteverteilung im Querschnitt der Rundknetwerkstücke war dabei homogen ausgeprägt. Darüber hinaus konnten in Abhängigkeit von den Prozessbedingungen unterschiedliche Eigenspannungsverteilungen entlang der Oberfläche erzeugt werden.

\section{Introduction}

Rotary swaging is an established incremental cold forming process for axisymmetric workpieces, such as axle shafts and steering spindles [1]. In infeed rotary swaging the form-

\footnotetext{
Dhia Charni

charni@iwt-bremen.de

Svetlana Ortmann-Ishkina

ishkina@bime.de

Marius Herrmann

herrmann@bime.de

Christian Schenck

schenck@bime.de

Jérémy Epp

epp@iwt-bremen.de
}

ing takes place mainly in radial direction. During the process, the dies rotate around the workpiece and strike simultaneously towards the center of the swaging axle, while the workpiece is axially fed into the swaging unit, see Fig. 1a. The simultaneous closing of the dies creates forces that act

1 Leibniz Institute for Materials Engineering-IWT, Badgasteiner Str. 3, 28359 Bremen, Germany

2 Bremen Institute for Mechanical Engineering-bime, University of Bremen, Badgasteiner Str. 1, 28359 Bremen, Germany

3 MAPEX Center for Materials and Processing, Bibliothekstr. 1, 28359 Bremen, Germany

4 University of Bremen, Bibliothekstr. 1, 28359 Bremen, Germany 
a

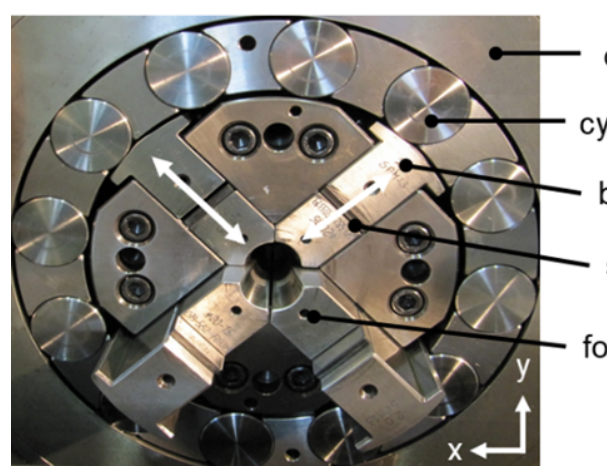

b outer ring

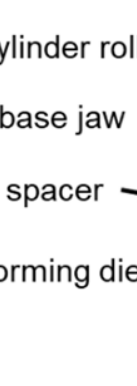

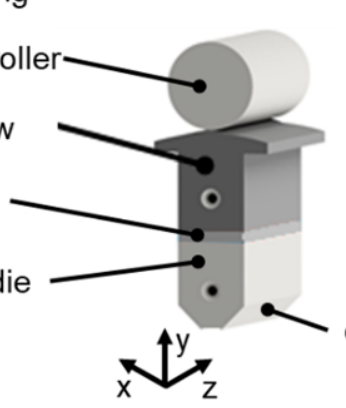

c
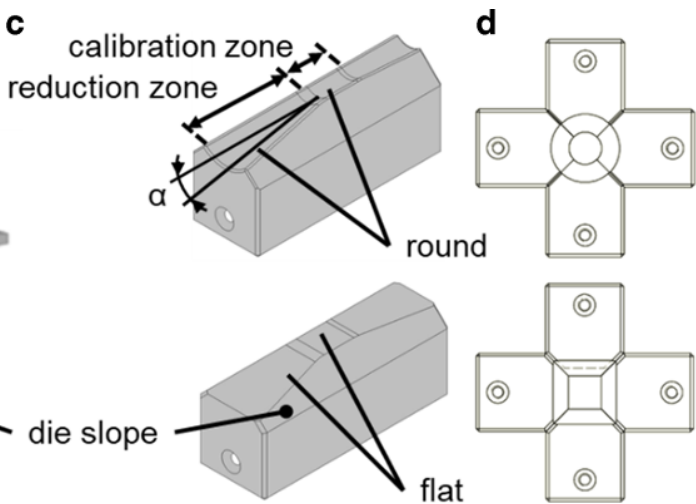

Fig. 1 Infeed rotary swaging: a Swaging head. b Pressure column. c Round and flat swaging die. d Die assembly

on the workpiece and lead to plastic deformations. The radial stroke of the dies is generated by passing of base jaws (with a cam) on the cylindrical rollers. The height of stroke is limited by the contact of the slope of the dies that touch each other, see Fig. 1.

Components produced by this process are mainly used in the automotive industry [2]. The semi-finished products are plastically formed incrementally, until the end-geometry is achieved. The process is mainly designed with regard to this geometric change and the achievable quality. Components with narrow tolerances of the diameter with $\pm 0.01 \mathrm{~mm}$ and high-quality surfaces with roughness $S_{a} \leq 0.5 \mu \mathrm{m}$ can be produced [1]. However, the achievable qualities depend on the initial state of the semi-finished product and the overall plastic deformation. But also process parameters influence the workpiece quality. The surface finish strongly depends on the feed rate of the workpiece [3], whereas the variation of the final diameter mainly depends on the overall deformation degree [4].

Additionally to the geometric properties also the static and dynamic strengths are influenced by work hardening and the introduction of residual stresses. The formation of these intrinsic properties depends on the material flow, especially on the way the material was plastically formed. With infeed rotary swaging, the material experiences a complex material flow [5], resulting in different levels of strain and compression in the different regions of the die [6]. In addition to the semi-finished product, this is mainly determined by the process control, the machine and the actual course of the process. The interaction of these numerous influencing factors are still not completely understood resulting in the produced parts being tolerated in practice only with regard to their geometric properties, without specifications on the intrinsic component properties. However, such properties as residual stresses, cold-working and the resulting mechanical properties, in particular the fatigue strength, have so far hardly been taken into account in the process design.

Amely at al. investigated the residual stresses after cold radial forging and found that the distribution of residual stresses at the inner and outer surface in the axial direction of tubes is uniform. They found tensile stress at the outer surface and compressive stresses at the inner surface of the tube [7]. Ghaei at al. described in FE-simulation a dependence of the geometry of the die to axial stresses in steel tubes [8]. Further FEM-study by Liu showed that the material flow at the beginning and the end of tube reduction zone, features the highest local plastic deformation. Moreover, the most active regions of strain are located on the inner and outer surface of the tube during the process [9]. Also Darki investigated rotary swaging by numerical methods and performed a radial forging with two stages [10] and determined that in addition to the uniform distribution of the residual stresses at the outer and inner surface, the maximum residual stresses were generated in the first process stage. Experimental investigation by neutron diffraction analyses of cold rotary swaged tungsten heavy alloy WNiCo showed, that the residual stresses and their distribution within the semi-finished product were not homogeneous. Also fluctuations between positive and negative values especially in the center of the workpiece were found [11].

Magnetic hardening by rotary swaging of Fe $50 \mathrm{Co} 50$ was investigated by Gröb et al. and showed an achievable increase in coercive field strength from 150 to $3500 \mathrm{~A} / \mathrm{m}$ before the limit of formability of the material was reached [12]. Another property studied was corrosion resistance, rotary swaging was carried out by Chuvil'deev et al. on the material $\mathrm{Ti}-2.5 \mathrm{Al}-2.6 \mathrm{Zr}$. They found that the processrelated grain refinement increased the electrochemical corrosion resistance. Hence, it was demonstrated that the grain refinement was not homogeneous over the cross-section, and it was higher for the grains near the surface compared to the grains in the core due to the different accumulated plastic deformation [13]. Moreover, $\mathrm{Al}-\mathrm{Cu}$ composite materials were produced by rotary swaging and examined regarding their mechanical and electrical properties. As a result, Kocich et al. showed that increasing strength through work hardening with increased degree of deformation improved 
the bonding of $\mathrm{Al}$ and $\mathrm{Cu}$ [14]. In addition, the production of this composite by rotary swaging led to improved electrical conductivity. X-ray diffraction investigations were carried out on the $\mathrm{Al}-\mathrm{Cu}$ composite materials produced by rotary swaging, showing even a decrease in the residual stresses in comparison to the initial state [14]. In addition, a study using neutron diffraction proved that rotary swaging with a higher total deformation (diameter reduction $10 \mathrm{~mm} \rightarrow 5 \mathrm{~mm}$, deformation degree $\phi=1.39$ ) leads to a more inhomogeneous distribution of the radial and tangential residual stress components across the cross-section when compared to a rotary swaging process with a lower total deformation (diameter reduction $10 \mathrm{~mm} \rightarrow 7.5 \mathrm{~mm}$, deformation degree $\phi=0.58$ ) [15].

In the present study the influence of the process parameters on the workpiece properties was studied after rotary swaging of S355/E355 steel and an overview about the intrinsic properties generated by the process are presented. The focus of the investigations was set on the changes of the resulting mechanical properties, in particular the tensile as well as the fatigue properties. Furthermore, the introduction of residual stresses at the surface are presented and correlated with the changes in the fatigue properties. Finally, the residual stress stability was assessed under thermal and mechanical loading to demonstrate the stability of the residual stresses generated by rotary swaging under common service conditions.

\section{Materials and methods}

\subsection{Rotary swaging setup}

The tests were carried out using a rotary swaging machine HE-32 (Felss Holding GmbH, Königbach-Stein, Germany) with two different die sets, see Fig. 1c and Fig. 1d. First, flat swaging dies with a flat surface in both the reduction and the calibration zone were used. By this geometry, the four closed dies form a square with an inscribed circle diameter of $15 \mathrm{~mm}$. The advantage of this process conduction, is that there is no uncontrolled workpiece rotation during the process. The second die set features a round reduction and calibration zone. The reduction zone was covered with a spraycoated tungsten carbide layer to increase the effective friction between the dies and the workpiece which reduces the axial reaction force during the process. The resulting die geometry by closing results in a circle diameter of $15 \mathrm{~mm}$ (Deformation degree $\phi=0.58$ ). Both die sets were made out of 1.2379 steel with a hardness of $62 \pm 2$ HRC. They had a die angle of $\alpha=10^{\circ}$ with a length of the calibration zone of $20 \mathrm{~mm}$. The stroke frequency of dies during the process was kept constant at $\mathrm{f}_{\mathrm{st}}=35 \mathrm{~Hz}$ and the stroke height was set to $h_{T}=1 \mathrm{~mm}$ for each pressure column, see Fig. $1 \mathrm{~b}$. The feed per stroke for the workpiece was set to $1_{\mathrm{st}}=0.46 \mathrm{~mm} /$ stroke (slow) and $1_{\mathrm{st}}=1.38 \mathrm{~mm} / \mathrm{stroke}$ (fast). The stroke following angle $\Delta \phi$ during infeed rotary swaging was arbitrary or it was set to $\Delta \phi=0^{\circ}$. This angle describes the relative rotating motion between die and workpiece. However, the arbitrary stroke following angle $\Delta \phi$ could differ in its value (low or high) due to the different braking torque, which influences the rotation of the workpiece. To achieve the stroke following angle $\Delta \phi=0^{\circ}$ the workpiece was freely rotated at the same angular velocity as the swaging axle by using soft clamping. The workpieces used in this investigation were cold-drawn steel tubes E355 (1.0580) and cold drawn steel bars S355 (1.0570) with an initial length of $\mathrm{L}_{0}=300 \pm 0.85 \mathrm{~mm}$ and a diameter of $\mathrm{d}_{0}=20 \pm 0.30 \mathrm{~mm}$. The tubes wall thickness was $\mathrm{s}_{0}=3 \mathrm{~mm}$ (specified by the manufacturer). In order to study the residual stress generation by rotary swaging, the cold drawn samples were annealed to eliminate any pre-existing residual stresses. However, both material states, as cold drawn and annealed were used in the present investigations, in order to evaluate the effect of the initial material condition on the properties after swaging. Annealing heat treatment before forming was carried out in a vacuum furnace at $890^{\circ} \mathrm{C}$ for $5 \mathrm{~h}$, followed by slow cooling until room temperature.

All rotary swaging experiments were carried out at room temperature, with mineral oil Condocut KNR 22 for lubrication of swaging unit as well as workpiece. The different experimental conditions which were used for rotary swaging are summarized in Table 1.

Table 1 Setup of rotary swaging experiments

\begin{tabular}{|c|c|c|c|c|c|}
\hline $\begin{array}{l}\text { Condi- } \\
\text { tion }\end{array}$ & $\begin{array}{l}\text { Workpiece } \\
\text { geometry }\end{array}$ & $\begin{array}{l}\text { Initial } \\
\text { state }\end{array}$ & $\begin{array}{l}\text { Die } \\
\text { shape }\end{array}$ & $\begin{array}{l}\text { Feed per } \\
\text { Stroke } \\
1_{\text {St }}, \mathrm{mm} / \\
\text { stroke }\end{array}$ & $\begin{array}{l}\text { Stroke } \\
\text { following } \\
\text { angle } \Delta \phi\end{array}$ \\
\hline IBA & Bars & Annealed & - & - & - \\
\hline ITA & $\begin{array}{l}\text { Bars/ } \\
\text { Tubes }\end{array}$ & Annealed & - & - & - \\
\hline ITC & Tubes & $\begin{array}{l}\text { Cold } \\
\text { drawn }\end{array}$ & - & - & - \\
\hline BAFS0 & Bars & Annealed & Flat & 0.46 & $0^{\circ}$ \\
\hline BAFF0 & Bars & Annealed & Flat & 1.38 & $0^{\circ}$ \\
\hline TAFS0 & Tubes & Annealed & Flat & 0.46 & $0^{\circ}$ \\
\hline TCFS0 & Tubes & $\begin{array}{l}\text { Cold } \\
\text { drawn }\end{array}$ & Flat & 0.46 & $0^{\circ}$ \\
\hline TARSH & Tubes & Annealed & Round & 0.46 & $\begin{array}{l}\text { Arbitrary } \\
\text { high }\end{array}$ \\
\hline TCRSH & Tubes & $\begin{array}{l}\text { Cold } \\
\text { drawn }\end{array}$ & Round & 0.46 & $\begin{array}{l}\text { Arbitrary } \\
\text { high }\end{array}$ \\
\hline TCRSL & Tubes & $\begin{array}{l}\text { Cold } \\
\text { drawn }\end{array}$ & Round & 0.46 & $\begin{array}{l}\text { Arbitrary } \\
\text { low }\end{array}$ \\
\hline TCRS0 & Tubes & $\begin{array}{l}\text { Cold } \\
\text { drawn }\end{array}$ & Round & 0.46 & $0^{\circ}$ \\
\hline
\end{tabular}




\subsection{Residual stress measurement}

The residual stresses were measured in the axial direction at the surface in the steady state region over a line of $40 \mathrm{~mm}$ along the axial direction, see Fig. 2. The residual stresses are assumed to be comparable at the surface along the tangential position. All residual stress lines were measured at the same start point, around $55 \mathrm{~mm}$ from each sample shoulder. The residual stress measurements were performed with a diffractometer Type ETA 3003 (GE inspection technologies, Ahrensburg, Germany) equipped with a position sensitive detector. A beam of $1 \mathrm{~mm}$ diameter with Vanadium filtered $\mathrm{Cr}-\mathrm{K} \alpha$ radiation was used. All residual stress measurement were calculated using the $\sin ^{2} \psi$-method on the $\{211\}$ diffraction peak of $\alpha$-iron at along $13 \psi$-angles between $-45^{\circ}$ and $+45^{\circ}$ and X-ray elastic constant $1 / 2 \mathrm{~S} 2=5.8110^{-6} \mathrm{MPa}^{-1}[16]$. The full width at half maximum (FWHM) of the diffracted peaks was also evaluated to obtain additional information on the microstructure and microstresses. The FWHM allows a quantitative evaluation of the hardness and microstrain distribution in cold formed non-hardened steel [17].

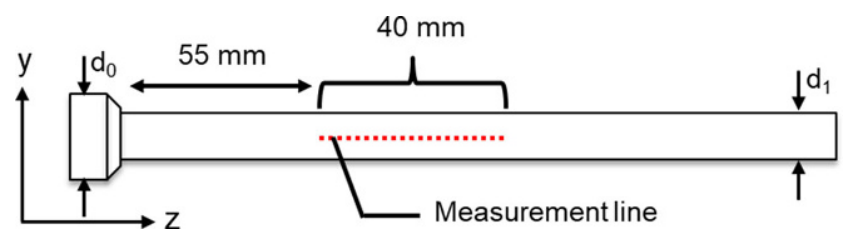

Fig. 2 Sketch of a swaged workpiece showing the position of outer surface residual stress measurements

\subsection{Characterization of mechanical properties}

In this study, the modifications of both static and dynamic mechanical properties by rotary swaging were investigated. To evaluate the static mechanical modifications generated by rotary swaging, tensile tests were performed. Tensile specimens of identical geometry were taken from annealed bars before and after rotary swaging in condition BAFS0, see Fig. 3. The samples taken from the rotary swaged bar included the outer surface. The annealed state was analyzed to ensure residual stress free state without cold-working and homogeneous overall properties to eliminate any possible interaction with the previous manufacturing process. The samples were cut by electro-discharge-machining and the surface was finished by grinding the surfaces, except for the surface that previously was the outer surface of the rotary swaged bar to keep the residual stresses generated at the surface of the rotary swaged bar BAFS0. Each ground surface was then subject to electrochemical etching using a solution of $\mathrm{H}_{3} \mathrm{PO}_{4}$ and $\mathrm{H}_{2} \mathrm{SO}_{4}$ to remove any influence from the sample preparation. The samples were submitted to a tensile test controlled by displacement until failure with a displacement rate of $6.66 \mu \mathrm{m} / \mathrm{s}$ corresponding to a strain rate of $0.001 / \mathrm{s}$ approximately. The strain was measured using a camera system that follows the speckle pattern at the center part of the sample in a region of about $2 * 4 \mathrm{~mm}$.

Additionally, the depth profile of the hardness was also measured in the longitudinal section along the radial position using the Vickers method with a weight of $100 \mathrm{~g}$ in both tubes and bars before and after rotary swaging. For this, longitudinal sections were cut by electro-discharge machining and polished before hardness depth profile measurements to ensure minimal material modification at the tested surface and good surface quality, see Fig. 4. Micrographs were also taken near the outer surface of each sample evaluation
Fig. 3 Overview of tensile test samples. a cut from annealed bar before rotary swaging. $\mathbf{b}$ cut from annealed rotary swaged bar with flat dies (BAFS0). c tensile test geometry a

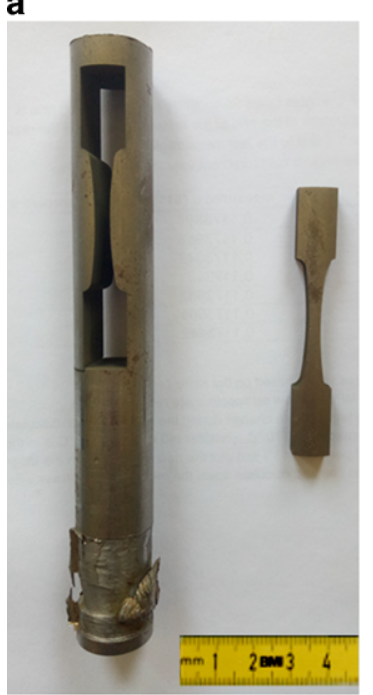

b

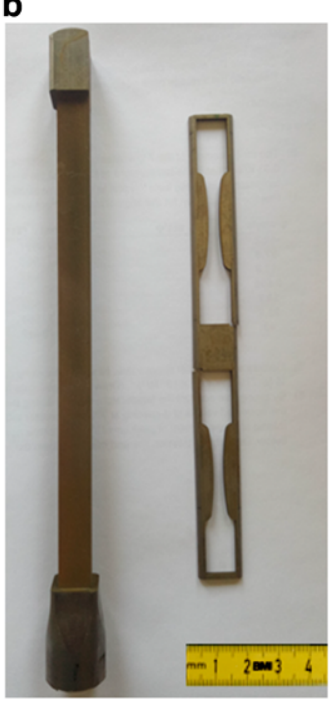

c

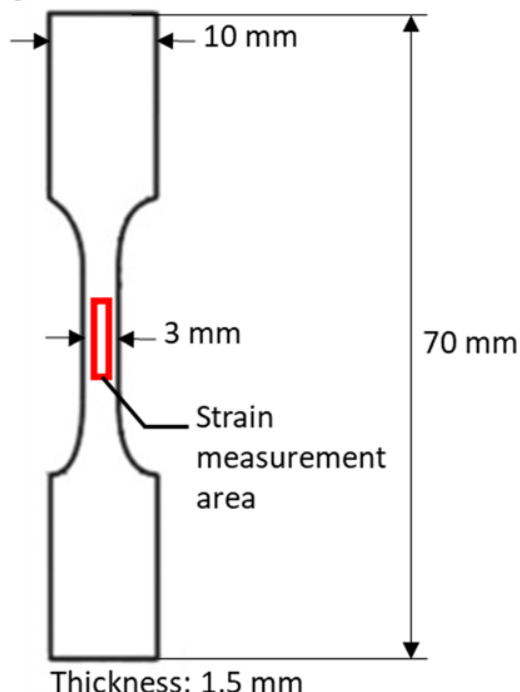



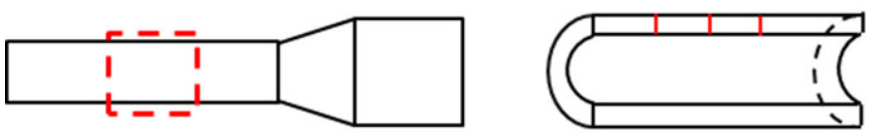

tube

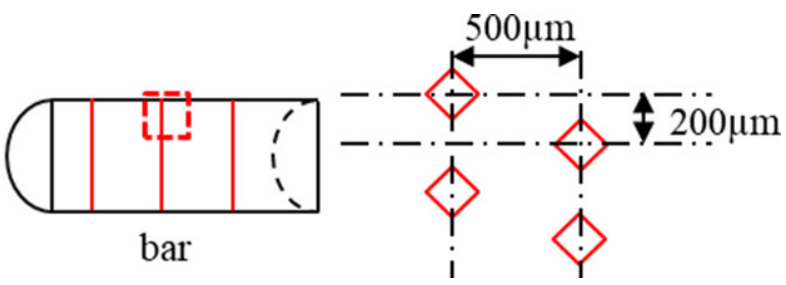

Fig. 4 Hardness depth profile measurement location

of the microstructure by optical microscopy (ZEISS Axiophot, Germany) with 500:1 magnification after etching using a $3 \%-\mathrm{HNO}_{3}$ alcoholic solution.

To evaluate the modification of the dynamic mechanical properties by rotary swaging, three-point bending fatigue test was performed. The cyclic tests were carried out using an electromagnetic pulser Rumul 50 (Russenberger, Switzerland) capable of applying a nominal load up to $50 \mathrm{kN}$ and a cyclic load amplitude up to $50 \mathrm{kN}$. To test the impact of the rotary swaging on the fatigue life, samples of rotary swaged S355 bars according to parameter setups BAFS0 and BAFF0 were tested and compared with samples in initial state which were machined and annealed (IBA) after the cutting process to have the same geometry as the swaged counterpart. Both rotary swaging processes produced samples with a square shaped section with a thickness of $15.5 \mathrm{~mm}$ on average. The distance between the outer supporting fixtures was set to $120 \mathrm{~mm}$. First the sample was loaded to the nominal amplitude before gradually adding the cyclic loading building up during the first 1000 cycles approximately until reaching the maximum load. The load amplitude used for the testing of the annealed undeformed S355 bars (IBA) corresponded to the maximum surface tension under the middle punch ranging from $72 \%$ (9653N) to $124 \%(16733 \mathrm{~N})$ of the yield strength of this material state. Whereas for the rotary swaged samples, the load amplitude ranged from $98 \%(5792 \mathrm{~N})$ to $172 \%(11584 \mathrm{~N})$ of the yield strength of the initial annealed material state. The yield strength of both annealed and rotary swaged states are determined using the tensile tests previously described. The $\mathrm{R}$ ratio used was $\mathrm{R}=-0.1$ and the cyclic load frequency was around $54 \mathrm{~Hz}$. Each load level was tested 2 to 3 times in the low cycle region and 2 to 8 times in the high cycle region. The number of cycles corresponding to the survival of the sample was set at 5 million cycles. It was assumed that the fatigue strength obeys the Weibull distribution function. This function was fitted to the experimental results to determine the fatigue strength which corresponds to $50 \%$ probability of fatigue failure. The $\mathrm{S} / \mathrm{N}$ curves were determined using the Basquin line method [18].

Additionally, the residual stresses stability under repetitive mechanical load was also investigated by measurements at the opposite side of the middle punch of the three point bending test rig. Two different load levels were used at $81 \%$ and $105 \%$ of the yield strength of the rotary swaged material state (BAFF0) respectively $81 \%$ for the elastic loading and $105 \%$ for the plastic loading. The residual stresses were taken after interrupting the cyclic test at different numbers of cycles. Due to the high frequency of the machine and the gradual buildup of the machine controlled cyclic load, the first 1000 cycles were obsolete. Therefore, the first 100 load cycles were done manually and further cycles were machine controlled up to 1 million cycles. The residual stress at number of cycles of 1000 was skipped. Thermal stability was additionally investigated by heating BAFF0 rotary swaged samples to temperatures up to $200^{\circ} \mathrm{C}$ for different time durations to simulate possible service conditions of an actual component. The heating was performed using an electric furnace without protective atmosphere. The residual stress was measured using the XRD as described and averaged from 2 measurement points at the surface of each sample and each heating experiment was performed 2 to 3 times for improved statistics. To better quantify the residual stress change on different samples (starting at different pre-heating residual stress), the measured residual stress $\sigma^{E S}(t)$ was normalized to the initial residual stress values $\sigma_{0}^{E S}$.

\section{Results}

\subsection{Mechanical properties and microstructure}

The tensile test results of both annealed undeformed and rotary swaged BAFS0 state are illustrated in the engineering stress strain curves shown in Fig. 5. The yield strength

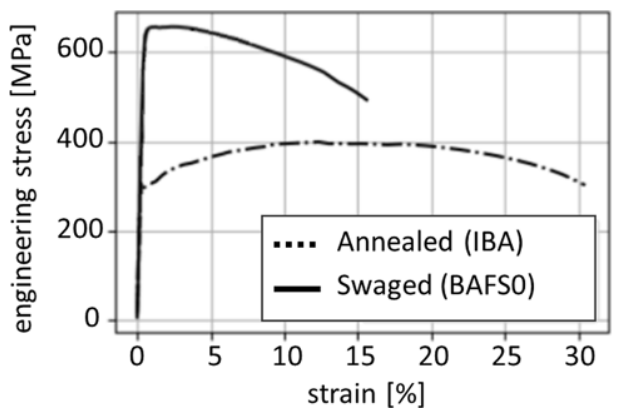

Fig. 5 Comparison of the tensile curves of S355 samples before (IBA) and after rotary swaging (BAFS0) 

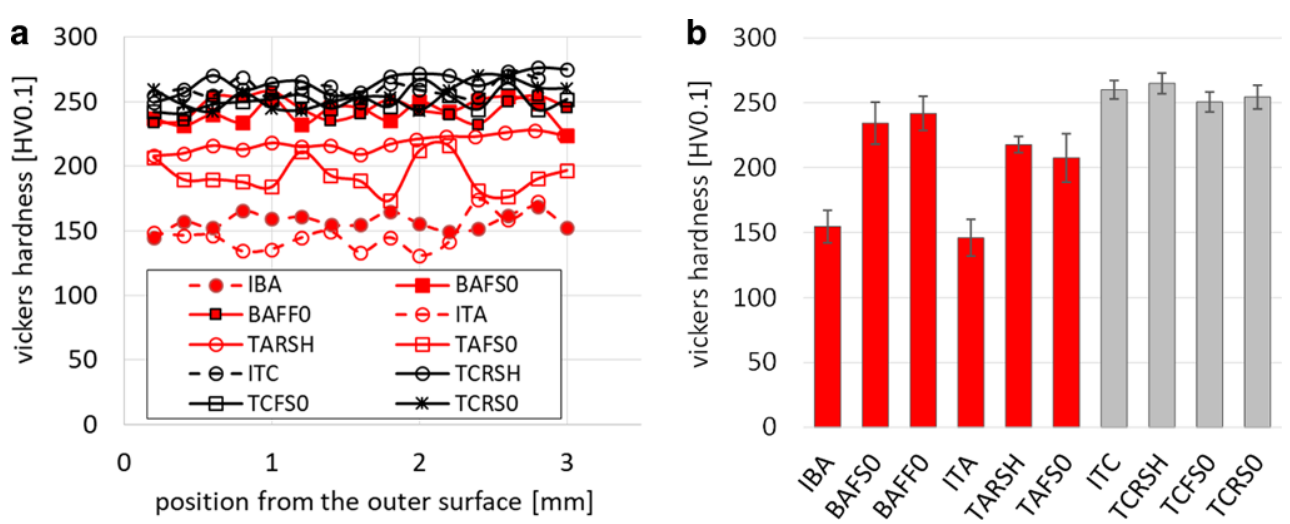

Fig. 6 a Hardness depth profiles measured over the radial position and $\mathbf{b}$ average hardness in the thickness of tubes and bars in different conditions, $I B A$ annealed initial state bar, BAFSO annealed bar, flat dies, slow feeding, free rotation, $B A F F O$ annealed bar, flat dies, fast feeding, free rotation, TARSH annealed tube, round dies, slow feeding, clamped with high rotation, TAFSO annealed tube, flat dies, slow feeding, free rotation, IC cold drawn initial state, TCRSH cold drawn tube, round dies, slow feeding, clamped with high rotation, TCFSO cold drawn tube, flat dies, slow feeding, clamped with free rotation, TCRSO cold drawn tube, round dies, slow feeding, clamped with free rotation

$\mathrm{Rp}_{0.2}$ has significantly increased from $315 \mathrm{MPa}$ in the initial state to $640 \mathrm{MPa}$ due to the work hardening effect of rotary swaging. This increase came with a significant decrease of the maximum elongation at rupture from $30 \%$ down to $16 \%$. It should be mentioned that one of the surfaces of the sample cut from the rotary swaged bar (BAFF0) had homogeneous compressive residual stresses around $-315 \mathrm{MPa}$ previously generated by the rotary swaging process whereas the sample cut from the center of the annealed bar (IBA) was residual stress free.

This work hardening effect can also be seen in the results of the hardness tests, see Fig. 6. Since the measured hardness is almost constant across the entire thickness, only data in the first $3 \mathrm{~mm}$ below the surface will be displayed for clarity reasons. The hardness of the initial cold drawn state is significantly reduced by almost 115 HV0.1 after the annealing heat treatment. Subsequent rotary swaging introduced an increase of hardness from 145 HV0.1 to 208 HV0.1 on average for all the annealed tubes. A slight difference can be seen between the round annealed tube (TARSH) and the square annealed tube (TAFS0) with TAFS0 having slightly lower hardness and hardness fluctuation along the thickness. Similarly, the hardness is increased from 154 HV0.1 to 238 HV0.1 on average for all annealed bars, showing no pronounced effect of the feeding velocity on the hardness development. On the other hand, hardness of the cold drawn tubes in initial state is already high and does not show any increase after rotary swaging, remaining around $260 \mathrm{HV} 0.1$. This shows that the cold drawn tubes have reached their maximum work hardening and further cold forming does not increase the hardness. The hardness results of the variant TCRSL were similar to the variant TCRSH and therefore were not included for visibility reasons. Overall, the hardness is almost homogenous along the axial direction and also within the thickness of both tubes and bars.

The examination of surface near microstructure of the different conditions can be seen in Fig. 7. The annealed initial material state (IBA) exhibit a slight decarburized layer of about $20 \mu \mathrm{m}$ thickness and presents larger but equiaxed grains particularly when compared to the cold drawn initial material state (ITC) which shows a finer microstructure with fine elongated grains in feed direction. A layer of axially elongated grains can be seen near the surface of the rotary swaged annealed bar variants BAFF0 and BAFS0. This is also seen on all annealed rotary swaged tube variants as well as in a previous studies $[19,20]$. This can be explained by the softer nature of the ferrite layer near the surface which deforms strongly duruing the process. No obvious difference can be seen between the rotary swaged bar variants BAFF0 and BAFS0 formed with different feeding velocity. Furthermore, no significant difference can be seen between the variants TCRSH and TCFSO which were processed with different die geometry (flat and round) and stroke following angle.

\subsection{Surface residual stresses}

The axial residual stresses on the surface of the annealed rotary swaged tubes by flat dies with stroke following angle of $\Delta \phi=0^{\circ}$ (TAFS0) and the cold drawn counterpart (TCFS0) are shown in Fig. 8. The residual stresses at the surface of the annealed tubes in initial state had a value of $7 \mathrm{MPa} \pm 5 \mathrm{MPa}$ while in cold drawn tubes they were $-114 \mathrm{MPa} \pm 9 \mathrm{MPa}$. The FWHM of both cold drawn and annealed initial states remain both at lowest level due to large crystallites. For the swaged tubes, the distribution of residual stresses along the workpieces within the measured length of $40 \mathrm{~mm}$ is quite homogenous for both cases. 
Fig. 7 Micrographs of the longitudinal section near the surface of the part before and after rotary swaging. Annealed state on the left and cold drawn state on the right

Fig. 8 Axial residual stresses for swaged tubes using flat dies with annealed and cold drawn initial state
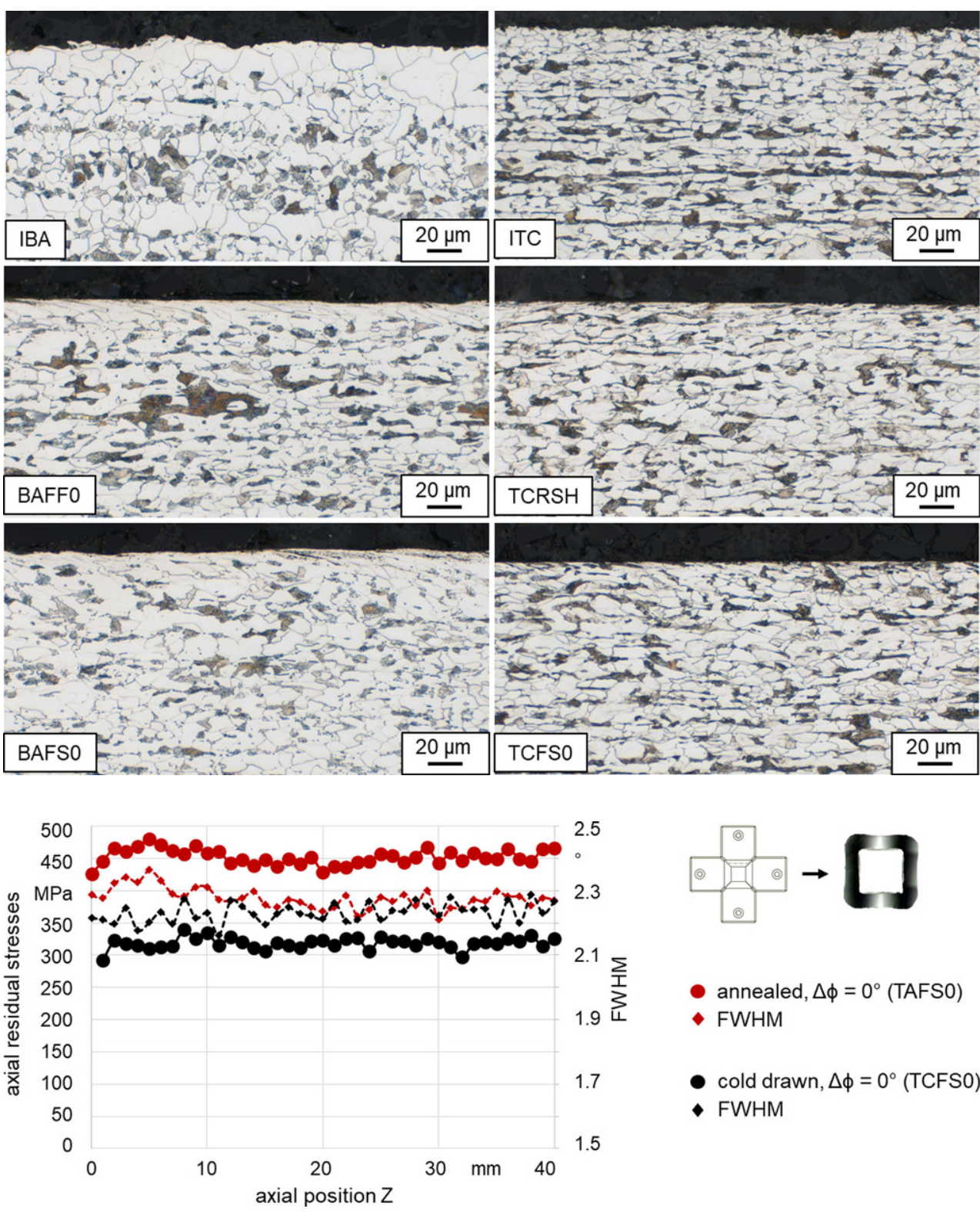

- annealed, $\Delta \phi=0^{\circ}$ (TAFSO)

- FWHM

- cold drawn, $\Delta \phi=0^{\circ}$ (TCFSO)

- FWHM
However, the heat-treated tubes show increased tensile residual stresses by about $150 \mathrm{MPa}$ after rotary swaging compared to the cold drawn tubes. On the other hand, the FWHM distributions in both conditions are rather similar, with the annealed condition slightly above the cold drawn initial state. The difference in residual stress between the cold-drawn and the annealed state at the surface can be attributed to the more pronounced deformation of the soft ferrite grain layer directly at the surface of the annealed initial condition, leading to higher tensile stresses than in the cold drawn initial state.

Fig. 9a presents the distribution of residual stresses for the formed round tubes. The residual stresses of the swaged sample with arbitrary high stroke following angle $\Delta \phi$ and annealed initial state (TARSH) fluctuated strongly from negative values about $-430 \mathrm{MPa}$ to local peaks with up to $+170 \mathrm{MPa}$, see Fig. 9a. The variation of the axial residual stresses was slightly less pronounced at the outer surface of the cold drawn counterpart (TCRSH). Most values were about $-300 \mathrm{MPa}$ (TCRSH), but also here, local peaks up to low tensile values are present. Regarding the FWHM distribution, slight periodic fluctuation can be observed in the annealed condition, while the cold drawn initial condition is less fluctuating and is also generally at lower level. This can be due to the already discussed effect of stronger deformation of the ferrite layer in the annealed state, leading to higher work hardening and therefore higher FWHM after swaging. Moreover, it has to be mentioned that the samples in cold drawn initial condition exhibit a pronounced crystallographic texture, while the annealed condition is more 

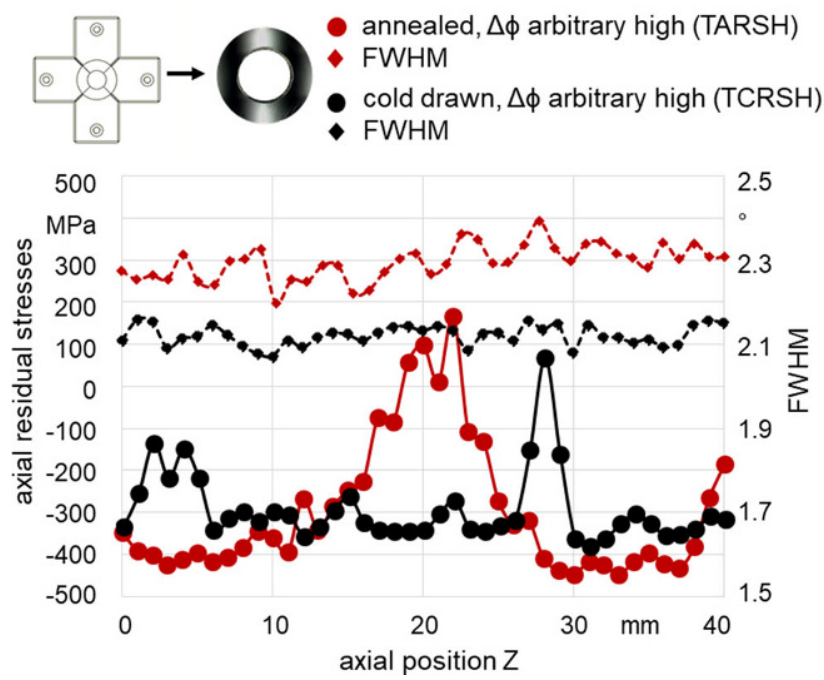

b

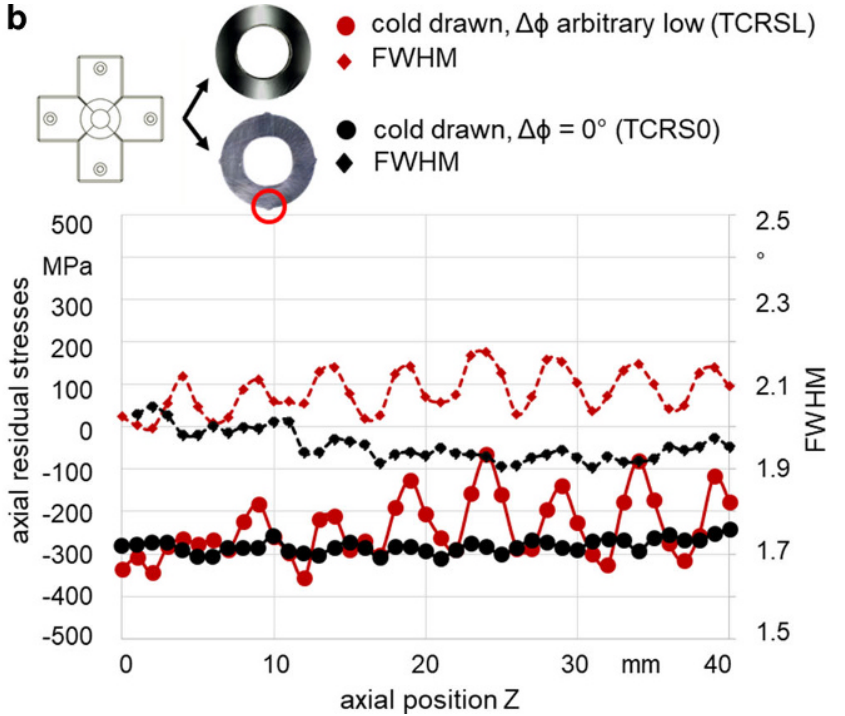

Fig. 9 Axial residual stresses for swaged tubes using round dies with: a fixed clamping and $\mathbf{b}$ freely rotating workpieces

or less texture-free. This difference is expected to influence the behaviour in subsequent deformation processes.

In Fig. 9b, a reduction of the fluctuation of the stress values can be observed for the cold drawn sample processed with arbitrary low stroke following angle $\Delta \phi$ (TCRSL). As already observed for the FWHM in Fig. 8a, here periodic residual stress variations between $-360 \mathrm{MPa}$ and $-70 \mathrm{MPa}$ as well as FWHM fluctuations with the same period can be observed. This demonstrates a clear influence of the rotary swaging process when the stroke following angle is nonzero. This effect was already observed in swaged tubes and it could be attributed to the overlapping of strokes from different dies that carry on process parameter fluctuations over the course of the forming process. This low reproducibility of the surface residual stresses could also be linked to the sensitivity of the process to external factors such as the workpiece axial deviation or the tube wall eccentricity [20]. On the other hand, cold drawn samples with a stroke following angle $\Delta \phi=0^{\circ}$ (TCRSO) exhibit axial residual stresses with almost constant negative value around $-300 \mathrm{MPa}$. In this case, also no pronounced periodic fluctuation of the FWHM can be observed while the average values are slightly below other conditions. However, a disadvantage of this process condition is the formation of small wings on the workpiece surface due to radial material flow between the dies, see sketch in Fig. 9b. Furthermore, The FWHM was slightly higher at the annealed variants compared to the cold drawn variants despite having lower hardness levels in the thickness. This effect is seen to be limited to the surface near region and can be attributed to the presence of highly deformed grains in the soft ferrite layer. Overall, the rotary swaged workpieces with the round dies showed a change of sign in the residual stresses com- pared to the workpieces rotary swaged with the flat dies. It was previously shown that this surface compressive residual stresses is only present in the surface near region up to $100 \mu \mathrm{m}$ below the surface of rotary swaged tubes [18, 19]. The cause of these stresses being compressive can be attributed to the combination of the die surface shape and the presence of the spray coated tungsten carbide layer in the reduction zone of the rounds dies which changes the friction conditions.

\subsection{Fatigue properties and residual stress stability}

Regarding the fatigue properties, the results of three point bending are illustrated by the $\mathrm{S} / \mathrm{N}$ curves in Fig. 10. The results show an increase in the fatigue strength from $232 \mathrm{MPa}$ of maximum surface stress for the annealed initial state (IBA) to $247 \mathrm{MPa}$ for BAFS0 and $261 \mathrm{MPa}$ for BAFF0. The applied maximum stress corresponding to the fatigue strength of the annealed state (IBA) was unexpectedly high which corresponds to $163 \%$ of the yield strength of the annealed state. This can be explained by work hardening occurring during the bending test in the plastic range [21]. Additionally, an effect of the high strain rate on the actual yield strength during dynamic load at $54 \mathrm{~Hz}$ can be expected. On the other hand, the applied maximum stress corresponding to the fatigue strength of the rotary swaged state corresponded to $81 \%$ of the respective yield strength for BAFS0 condition and $90 \%$ for BAFF0. Since both of these states were already exhibiting maximum work hardening due to the rotary swaging process, no further work hardening is expected to be occurring during the cyclic testing. Moreover, a small difference between the two investigated swaging processes can be observed. While both processes produced 
Fig. $10 \mathrm{~S} / \mathrm{N}$ curve with the $50 \%$ failure probability obtained by cyclic three-point bending for three material conditions. $I B A$ annealed initial state (bar), $B A F S O$ annealed bar, flat dies, slow feeding, free rotation, $B A F F O$ annealed bar, flat dies, fast feeding, free rotation
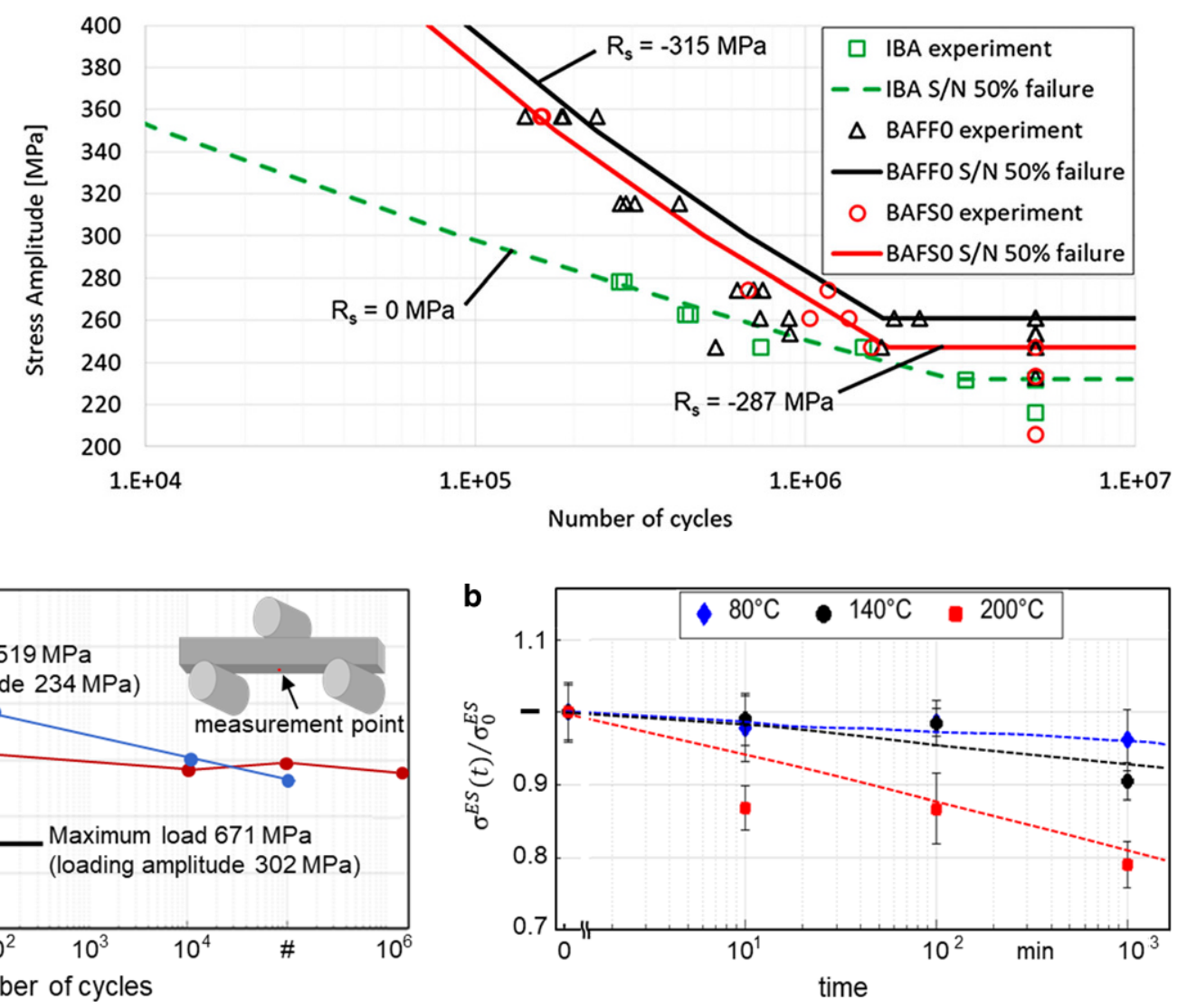

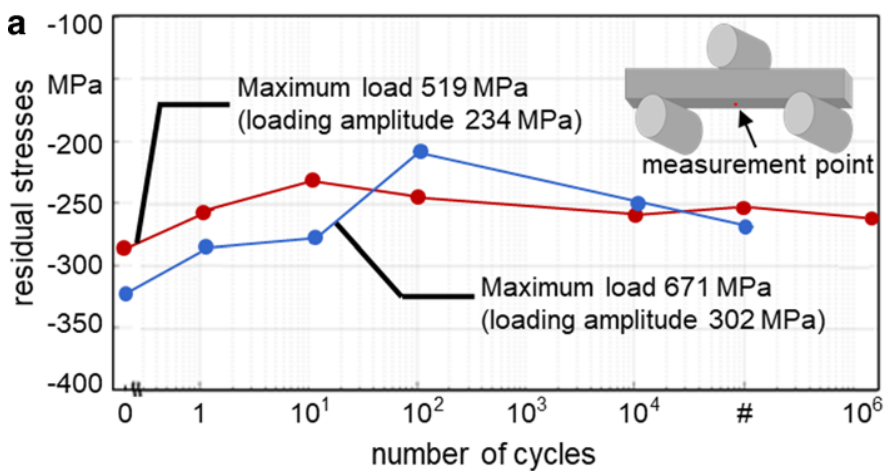

Fig. 11 Residual stress stability at the surface of BAFF0 samples: a under dynamic mechanical load and b under thermal load

samples with similar cold working (see hardness results in Fig. 6), the compressive axial residual stress values at the surface where slightly increased from $-287 \pm 11 \mathrm{MPa}$ for BAFS0 to $-315 \pm 56 \mathrm{MPa}$ for BAFF0, which can be seen to be the reason for the increased fatigue strength. Additionally, a change of the Basquin line slope can be seen between the undeformed state and the rotary swaged conditions. This is mainly attributed to the higher static yield strength after swaging, which is mainly affected by the strong work hardening induced by rotary swaging.

Finally, both mechanical and thermal stability of the residual stresses was investigated and the results are shown in Fig. 11. During cyclic bending load, the residual stresses remain almost unchanged during loading at maximum load of $519 \mathrm{MPa}$ ( $81 \%$ of the yield strength). However, at a maximum load of $671 \mathrm{MPa}$ (105\% of the yield strength), a decrease can be observed from 1 to 100 cycles which is then followed by an increase of the compressive residual stresses until 100,000 cycles. This can be attributed to plasticity effects that can occur at this level of bending load. The sample submitted to this bending load did not survive the cyclic test and fractured before 1 million cycle.

Regarding the thermal stability, the residual stresses are rather stable at temperatures up to $140^{\circ} \mathrm{C}$, where only about $10 \%$ of the initial residual stresses were relaxed after
$1000 \mathrm{~min}$ at this temperature. At a temperature of $200^{\circ} \mathrm{C}$ the relaxation is more pronounced, reaching a maximum of $21 \%$ of the initial value after $1000 \mathrm{~min}$.

\section{Conclusion}

In this study, the impact of rotary swaging on different material properties was investigated for different parameter setups and following statements can be drawn:

- The hardness and the flow curve proved a significant work hardening introduced by rotary swaging.

- The hardness increase by rotary swaging is mostly homogeneous over the cross section of both annealed tubes and bars and is mostly independent of the considered process parameters such as feeding velocity, stroke following angle and the die surface shape. However, no additional work hardening was introduced on cold drawn tubes after rotary swaging and the hardness remained the same and homogenous across the thickness.

- Fixing the stroke following angle at $0^{\circ}$ with flat or round die geometry leads to homogeneous surface residual stresses, compared to the conventional process where strong fluctuations are present. However, the die geome- 
try strongly influences the sign of the residual stresses in the surface region, which is attributed to the modified local deformation and changed friction condition between the swaging dies and the workpiece.

- Annealing before rotary swaging showed to increase the amplitude of surface residual stress fluctuations and yield lower hardness increase in the entire cross section in the case of tubes.

- The cyclic bending tests showed an increase in the fatigue properties by rotary swaging, which can be attributed to a combined effect of work hardening and compressive residual stresses in the surface region

- Surface residual stresses generated by rotary swaging were mostly stable under both mechanical and thermal loads.

Acknowledgements This project is funded by the Deutsche Forschungsgemeinschaft (German Research Foundation)-374789876 within the sub-project (EP 128/5-2 and KU 1389/16-2) "Control of component properties in rotary swaging process" of the priority program SPP 2013 "The utilization of residual stresses induced by metal forming".

Funding Open Access funding enabled and organized by Projekt DEAL.

Conflict of interest D. Charni, S. Ortmann-Ishkina, M. Herrmann, C. Schenck and J. Epp declare that they have no competing interests.

Open Access This article is licensed under a Creative Commons Attribution 4.0 International License, which permits use, sharing, adaptation, distribution and reproduction in any medium or format, as long as you give appropriate credit to the original author(s) and the source, provide a link to the Creative Commons licence, and indicate if changes were made. The images or other third party material in this article are included in the article's Creative Commons licence, unless indicated otherwise in a credit line to the material. If material is not included in the article's Creative Commons licence and your intended use is not permitted by statutory regulation or exceeds the permitted use, you will need to obtain permission directly from the copyright holder. To view a copy of this licence, visit http://creativecommons.org/licenses/by/4. $0 /$.

\section{References}

1. Rauschnabel E, Schmidt V (1992) Modern applications of radial forging and swaging in the automotive industry. J Mater Process Technol 35:371-383

2. Kienhöfer C, Grupp P (2003) Rundknettechnik Verfahren, Vorteile, Möglichkeiten. Verlag Moderne Industrie, Landsberg/Lech

3. Rong L, Nie Z, Zuo T (2016) FEA modeling of effect of axial feeding velocity on strain field of rotary swaging process of pure magnesium. Trans Nonferr Met Soc China 16:1015-1020
4. Lim SJ, Choi HJ, Na KH, Lee CH (2007) Dimensional characteristics of products using rotary swaging machine with four-dies. Solid State Phenom 124-126:1645-1648

5. Wu Y, Dong X, Yu Q (2015) Upper bound analysis of axial metal flow inhomogeneity in radial forging process. Int $\mathrm{J}$ Mech Sci 93:102-110

6. Liu Y, Liu J, Herrmann M, Schenck C, Kuhfuss B (2021) Material flow in Infeed rotary swaging of tubes. Materials 14:58

7. Ameli A, Movahhedy MR (2007) A parametric study on residual stresses and forging load in cold radial forging process. Int J Adv Manuf Technol 33:7-17

8. Ghaei A, Movahhedy MR (2007) Die design for the radial forging process using 3D FEM. J Mat Proc Tech 182:534-539

9. Liu Y, Herrmann M, Schenck C, Kuhfuss B (2019) Plastic deformation components in mandrel free Infeed rotary swaging of tubes. Proc Manuf 27:33-38

10. Darki S, Raskatov EY (2020) Analysis of the hot radial forging process according to the finite element method. Int J Adv Manuf Tech 110:1061-1070

11. Kunčická L, Kocich R, Hervoches C, Macháčková A (2017) Study of structure and residual stresses in cols rotary swaged tungsten heavy alloy. Mater Sci Eng A 704:25-31

12. Gröb T, Wießner L, Bruder E, Faske T, Donner W, Groche P, Müller C (2017) Magnetic hardening of Fe 50 Co 50 by rotary swaging. J Magn Magn Mater 428:255-259

13. Chuvil'deev VN et al (2019) Effect of severe plastic deformation realized by rotary swaging on the mechanical properties and corrosion resistance of near- $\alpha$-titanium alloy Ti-2.5Al-2.6Zr. J Alloys Compd 785:1233-1244

14. Kocich R, Kunčická L, Macháčková A, Šofer M (2017) Improvement of mechanical and electri-cal properties of rotary swaged AlCu clad composites. Mater Des 123:137-146

15. Kocich R, Kunčická L, Dvořák K, Macháčková A (2018) Rotary swaged laminated $\mathrm{Cu}-\mathrm{Al}$ com-posites: Effect of structure on residual stress and mechanical and electric properties. Mater Sci Eng A. https://doi.org/10.1016/j.msea.2018.11.026

16. Noyan IC, Cohen JB (1987) Residual stress measurements by diffraction and interpretation. Springer, New York

17. Epp J, Surm H, Hirsch T, Hoffmann F (2011) Residual stress relaxation during heating of bearing rings produced in two different manufacturing chains. J Mater Process Tech 211:637-643

18. Basquin OH (1910) The exponential law of endurance tests. Proc ASTM 10:625-630

19. Charni D, Ishkina S, Epp J, Herrmann M, Schenck C, Zoch HW, Kuhfuss B (2018) Residual stress generation in rotary swaging. In: Proceedings of the 5th International Conference on New Forming Technology (ICNFT 2018), Bremen, Germany, 18-21 September 2018

20. Ishkina S, Charni D, Herrmann M, Liu Y, Epp J, Schenck C, Kuhfuss B, Zoch H-W (2019) Influence of process fluctuations on residual stress evolution in rotary swaging of steel tubes. Materials 12(6):855

21. Broom T, Ham RK (1957) The hardening and softening of metals by cyclic stressing. Proc R Soc Lond A Math Phys Sci 242(1229):166-179 